\title{
AVALIAÇÃO DA CONTAMINAÇÃO POR MICRORGANISMOS PATOGÊNICOS E CUIDADOS COM ESCOVAS DENTAIS
}

\section{EVALUATION OF CONTAMINATION BY PATHOGENIC MICROORGANISMS AND CARE WITH TOOTHBRUSHES}

Amanda da Silva Nunes da Conceição ${ }^{1}$, Alicia da Silva Nunes da Conceição², Michelle Silva de Oliveira ${ }^{3}$, Diego de Andrade Teixeira ${ }^{4}$, José Massao Miasato ${ }^{5}$, Leila Chevitarese ${ }^{6}$, Luciana Alves Herdy da Silva ${ }^{7}$, Flávia Cariús Tesch Ferreira Alves ${ }^{8}$, Silvio Jorge Machado ${ }^{9}$

e321183

\section{RESUMO}

https://doi.org/10.47820/recima21.v3i2.1183

Introdução: Tão importante quanto à prática da escovação dos dentes, é a forma como estas escovas são armazenadas, uma vez que o incorreto armazenamento pode proporcionar a proliferação de microrganismos patogênicos, que podem acarretar danos ao indivíduo. Objetivo: O objetivo foi verificar se o armazenamento das escovas dentárias está sendo realizado de maneira correta, e verificar a existência de contaminação por microrganismos patogênicos. Materiais e Métodos: Foi coletado um total de 20 escovas de pacientes da Clínica de Odontopediatria de uma universidade privada do Rio de Janeiro. Foi realizado um questionário aos responsáveis contendo questões como idade, sexo, frequência de escovação, marca do creme dental, utilização de fio dental e antisséptico bucal, forma de armazenamento e o uso de aparelhos ortodônticos, móvel ou fixo. Após a coleta, as escovas foram levadas ao laboratório e o processo de identificação bacteriana ocorreu pela análise macroscópica das placas para identificação nos meios de cultura diferenciais, coloração de Gram e análise microscópica. Resultados e Discussão: A idade dos pacientes variou entre 4 e 13 anos, $85 \%$ dos voluntários eram do sexo masculino, $80 \%$ escovavam os dentes 3 vezes ao dia e 65\% armazenavam a escova dental em recipientes em cima da pia e $65 \%$ das amostras estavam contaminadas por Staphylococcus aureus. O uso da escova dental é fundamental na higiene oral, entretanto, este instrumento pode ser fonte de contaminação quando não armazenadas de forma adequada. Conclusão: Todas as escovas avaliadas apresentaram algum tipo de contaminação, independente da forma de armazenamento.

PALAVRAS-CHAVE: Escova dental. Contaminação. Descontaminação. Armazenamento.

\begin{abstract}
\footnotetext{
1 Universidade do Grande Rio (UNIGRANRIO)

2 Universidade do Grande Rio (UNIGRANRIO)

3 Universidade do Grande Rio (UNIGRANRIO)

4 Universidade do Grande Rio (UNIGRANRIO)

5 Universidade do Grande Rio (UNIGRANRIO)

6 Universidade do Grande Rio (UNIGRANRIO)

7 Universidade do Grande Rio (UNIGRANRIO)

8 Universidade do Grande Rio (UNIGRANRIO)

9 Universidade do Grande Rio (UNIGRANRIO)
}

Introduction: As important as the practice of brushing teeth is the way these brushes are stored since incorrect storage can lead to the proliferation of pathogenic microorganisms, which can cause damage to the individual. Objective: The objective was to verify if the storage of toothbrushes is being carried out correctly and verify contamination by pathogenic microorganisms. Materials and Methods: A total of 20 brushes were collected from patients at the Pediatric Dentistry Clinic of a private university in Rio de Janeiro. A questionnaire was applied to the guardians, containing questions such as age, gender, brushing frequency, the toothpaste brand, use of dental floss and mouthwash, the form of storage, and the use of orthodontic appliances, mobile or fixed. After collection, the brushes were taken to the laboratory. The bacterial identification process was carried out by macroscopic analysis of the plates for identification in differential culture media, Gram staining, and microscopic analysis. Results and Discussion: The age of the patients ranged 


\section{RECIMA21 - REVISTA CIENTÍFICA MULTIDISCIPLINAR ISSN 2675-6218}

between 4 and 13 years, 85\% of the volunteers were male, $80 \%$ brushed their teeth three times a day, $65 \%$ stored the toothbrush in containers above the sink, and $65 \%$ of the samples were contaminated by Staphylococcus aureus. The use of a toothbrush is essential for oral hygiene; however, this instrument can be a source of contamination when not stored properly. Conclusion: All evaluated toothbrushes showed some contamination, regardless of the way of storage.

KEYWORDS: Toothbrush. Contamination. Decontamination. Storage.

\section{INTRODUÇÃO}

Os levantamentos epidemiológicos evidenciam os graves problemas de saúde bucal que afetam os indivíduos nos diferentes países. As condições socioeconômicas e culturais das populações têm sido a responsável por inúmeros problemas relacionados com a saúde bucal. Até a década de 1990, a Odontologia no Brasil tinha sua atuação limitada à eliminação da dor, como objetivo de caráter curativo apenas. Com o tempo, passou-se a adotar uma filosofia onde o objetivo não era mais restrito à eliminação da dor, mas incluir também a abordagem da causa. Trata-se então de uma odontologia de vigilância, cujo princípio de atuação baseia-se na prevenção das doenças bucais, através do controle de seus fatores etiológicos. O controle do biofilme dentário pode ser realizado por meio da utilização de agentes mecânicos, químicos ou por uma associação entre ambos e os demais fatores através de orientações, sendo a escovação o principal. No entanto, tão importante quanto à prática da escovação dos dentes, é a forma como estas são armazenadas, uma vez que o incorreto armazenamento pode proporcionar a proliferação de microrganismos patogênicos, que podem acarretar danos ao indivíduo (SANCHES et al., 2001; PINTO et al., 1997).

As escovas dentárias são fontes de contaminação, de modo que podem atuar como meio de proliferação e de transmissão destes microrganismos. É o objeto mecânico universalmente mais aceito e utilizado na higiene bucal, e apresenta uma série de características, ditadas por padrões técnico-biológicos, de suma importância para o controle mecânico do biofilme dentário, esta que é o fator etiológico primário no desenvolvimento da doença periodontal (ARAÚJO et al., 2014, BALAPPANAVAR et al., 2009, SANCHES et al., 2001, SOARES et al., 2010).

Mesmo após sofrerem um processo de turbilhonamento, as cerdas ainda continuam apresentando um abundante crescimento bacteriano. Isto sugere uma forte união dos microrganismos entre si e entre seus substratos. É possível também que a contaminação destas escovas possa servir como instrumento de transmissão de microrganismos, por meio da abrasão existente entre a escova e a gengiva durante a escovação, ou por lesões já existentes na cavidade bucal. Escovas contaminadas por microrganismos encontrados na boca e no ambiente podem cooperar para o aparecimento de infecções cruzadas e autoinfecção (MARIN; MICHELS, 2017; SIQUEIRA JÚNIOR et al., 2011). 


\section{RECIMA21 - REVISTA CIENTÍFICA MULTIDISCIPLINAR ISSN 2675-6218}

A contaminação microbiana das escovas é influenciada diretamente pelos microrganismos da cavidade oral, que são capazes de se multiplicar entre as cerdas após o uso, e pelo ambiente onde são armazenadas. Logo, é necessário a criação de hábitos de higienização e armazenamento adequados para evitar a contaminação, pois, ainda que hábitos saudáveis de higiene bucal sejam praticados, pode haver contaminação de escovas (MOREIRA; CAVALCANTE, 2008). Além disso, quando as escovas dentais não são substituídas regularmente, e armazenadas em locais úmidos ou recipientes fechados, aumenta-se o risco de contaminação por diversos patógenos, tais como: Staphylococcus sp., Streptococcus sp., Aerococcus sp., Pseudomonas sp., Coliformes fecais, Streptococcus pyogenes, sendo este último responsável por faringite em crianças, entre outros (QUEIROS; PASSOS, 2019).

Mialhe et al. (2007) verificaram que boa parte dos graduandos do curso de Odontologia não secam as cerdas da escova, nem utilizam qualquer produto desinfetante após sua utilização, fato que pode favorecer o acúmulo microbiano nesse importante instrumento de higiene bucal. Silver et al. (1977) demonstraram esta possibilidade quando estudaram 36 indivíduos, logo após terem feito uso de suas escovas dentais, e detectaram a presença de uma mesma bactéria em 3 indivíduos. Sanches et al. (2001) encontrou os seguintes microrganismos, removidos das escovas: Streptococcus mutans, lactobacilos, enterobactérias, Staphylococcus aureus e leveduras. Estes mesmos autores avaliaram o emprego do antisséptico bucal a base de cloreto de cepitilpiridino (0,05\%) e solução alcoólica a 77\% V/V na desinfecção bacteriana de escovas dentárias. Concluíram que a solução alcoólica apresentou melhores resultados. No entanto, para Sato et al., (2004) a utilização do cetilpiridino na forma de spray foi considerada capaz de promover a desinfecção das escovas dentárias.

Em março de 2020, a Organização Mundial da Saúde (OMS) declarou pandemia de COVID19 (Sars-CoV-2). Este novo vírus que pode ser transmitido pelo contato direto, ou indireto, com as mucosas dos olhos, nariz ou boca. Nesse contexto, o vírus pode permanecer na boca, principalmente na língua, que é um grande reservatório de microrganismos. Com isso, uma boa higiene oral é necessária para reduzir a quantidade de vírus presente na mucosa oral de pacientes contaminados. Ademais, pelo risco de contaminação cruzada é importante garantir que escovas dentais de indivíduos que convivem na mesma residência não estejam armazenadas em um mesmo ambiente; também se recomenda que o tubo de dentifrício fluoretado não seja compartilhado. Alguns estudos mostram que o Sars-CoV-2 pode ser transmitido de forma indireta pela escova dental e, com isso, a fim de diminuir o risco de potencial reintrodução do vírus na cavidade oral, assim como a contaminação cruzada, sugere-se que a escova dental seja submetida a um processo de descontaminação (GONZÁLEZ-OLMO et al., 2020; LAMARCA et al., 2020; TEIXEIRA et al., 2021).

Desta forma, o objetivo desta pesquisa foi de verificar se as escovas dentárias dos pacientes da Clínica de Odontopediatria de uma universidade privada do Rio de Janeiro estão 


\section{RECIMA21 - REVISTA CIENTÍFICA MULTIDISCIPLINAR ISSN 2675-6218}

sendo armazenadas de forma correta, e verificar a existência de contaminação por microrganismos patogênicos.

\section{MATERIAIS E METODOS}

A pesquisa foi submetida e aprovada pelo Comitê de Ética em Pesquisa (CEP), CAEE n 20619519.0.0000.5283.

Foi coletado um total de 20 escovas de pacientes da Clínica de Odontopediatria de uma universidade privada do Rio de Janeiro. Foram considerados critérios de inclusão no estudo: pacientes que estavam em tratamento na Clínica de Odontopediatria e que os responsáveis assinaram o Termo de Consentimento Livre e Esclarecido.

Em um primeiro momento, foi realizado um questionário com 12 perguntas contendo questões como idade, sexo, frequência de escovação, marca do creme dental, utilização de fio dental e antisséptico bucal, forma de armazenamento e o uso de aparelhos ortodônticos, móvel ou fixo. Este questionário era respondido pelo responsável legal e, ao final, era entregue a este uma embalagem previamente esterilizada, para que a escova da criança fosse armazenada e transportada até a Clínica de Odontopediatria. A cada voluntário foi entregue uma nova escova dental.

Após a coleta, as escovas foram levadas ao Laboratório Multidisciplinar, inoculadas individualmente em tubos de ensaio contendo caldo Brain Heart Infusion (BHI) (Merck KGaA, Darmstadt, Alemanha), que cobria totalmente as cerdas das escovas; os tubos eram vedados com algodão hidrofóbico e incubados em estufa a $37^{\circ} \mathrm{C}$ durante 24 horas.

Depois desse período, as culturas crescidas no caldo BHI foram repicadas para os meios de cultura diferenciais e seletivos Ágar Eosina Azul de Metileno (EMB) (Merck KGaA, Darmstadt, Alemanha), Ágar Sabouraud Dextrose (Merck KGaA, Darmstadt, Alemanha), Ágar Sal Manitol (Merck KGaA, Darmstadt, Alemanha), pela técnica do esgotamento, sendo novamente levada a estufa durante $24-48$ horas a $37^{\circ} \mathrm{C}$, sendo identificados posteriormente os patógenos.

O processo de identificação bacteriana ocorreu pela análise macroscópica das placas para identificação nos meios de cultura diferenciais; foi realizada também a técnica de coloração de Gram de todas as diferentes colônias de bactérias para a identificação morfotintorial das bactérias Gram positivas e Gram negativas e, posteriormente, a análise microscópica.

Foi realizada a análise estatística descritiva dos dados.

\section{RESULTADOS}

Foram coletadas 20 escovas. A idade dos pacientes variou entre 4 e 13 anos, sendo $85 \%$ (17) do sexo masculino e 15\% (3) do sexo feminino. Cinco por cento (1) dos voluntários escovavam os dentes 2 vezes ao dia, 80\% (16) escovavam 3 vezes ao dia e 15\% (3) escovavam 4 vezes ao dia; nenhum voluntario relatou escovação apenas 1 vez ao dia. 


\section{RECIMA21 - REVISTA CIENTÍFICA MULTIDISCIPLINAR ISSN 2675-6218}

AVALIAÇ̃̃O DA CONTAMINAÇÃO POR MICRORGANISMOS PATOGÊNICOS E CUIDADOS COM ESCOVAS DENTAIS Amanda da Silva Nunes da Conceição, Alicia da Silva Nunes da Conceição, Michelle Silva de Oliveira, Diego de Andrade Teixeira, Amanda da Silva Nunes da Conceição, Alicia da Silva Nunes da Conceição, Michelle Silva de Oliveira, Diego de Andrade Teixeira,
José Massao Miasato, Leila Chevitarese, Luciana Alves Herdy da Silva, Flávia Cariús Tesch Ferreira Alves, Silvio Jorge Machado

Quanto ao momento da escovação, 28\% (13) responderam que escovam os dentes ao acordar/pela manhã/após o café da manhã, 25\% (12) após o almoço/à tarde, 28\% (13) noite/após o jantar/antes de dormir, 12\% (6) após as refeições, e 6\% (3) não informaram.

Quanto ao uso do fio dental, apenas $40 \%$ (8) dos voluntários utilizavam o fio dental, porém, $80 \%$ não notaram ou não relataram sangramento gengival.

Quanto à forma de armazenamento da escova dental, 35\% (7) informaram que armazenavam em um armário, enquanto 65\% (13) informaram que armazenavam sobre a pia dentro de um recipiente; destes, 35\% (7) utilizavam capa protetora nas cerdas da escova, e 70\% (14) tinham o hábito de secar a escova dental antes do armazenamento.

$\mathrm{Na}$ Tabela 1, é possível observar a prevalência dos microrganismos encontrados nas escovas dentais dos voluntários.

Tabela 1 - Total de microrganismos identificados em 20 amostras.

\begin{tabular}{lcc}
\hline \multicolumn{1}{c}{ Microrganismos } & N & $\%$ \\
\hline Staphylococcus aureus & 13 & $65 \%$ \\
Staphylococcus epidermidis & 11 & $55 \%$ \\
Escherichia coli & 4 & $20 \%$ \\
Enterobacter sp. & 8 & $40 \%$ \\
Streptococcus sp. & 1 & $5 \%$ \\
Pseudomonas aeruginosa & 2 & $10 \%$ \\
Candida sp. & 1 & $5 \%$ \\
& &
\end{tabular}

Fonte: Autores, 2022.

No Gráfico 1 podemos observar as marcas de dentifrícios utilizados pelos voluntários. 


\section{RECIMA21 - REVISTA CIENTÍFICA MULTIDISCIPLINAR ISSN 2675-6218}

AVALIAÇÃO DA CONTAMINAÇ̃̃O POR MICRORGANISMOS PATOGÊNICOS E CUIDADOS COM ESCOVAS DENTAIS Amanda da Silva Nunes da Conceição, Alicia da Silva Nunes da Conceição, Michelle Silva de Oliveira, Diego de Andrade Teixeira, José Massao Miasato, Leila Chevitarese, Luciana Alves Herdy da Silva, Flávia Cariús Tesch Ferreira Alves, Silvio Jorge Machado

Gráfico 1 - Marcas de dentifrícios utilizados

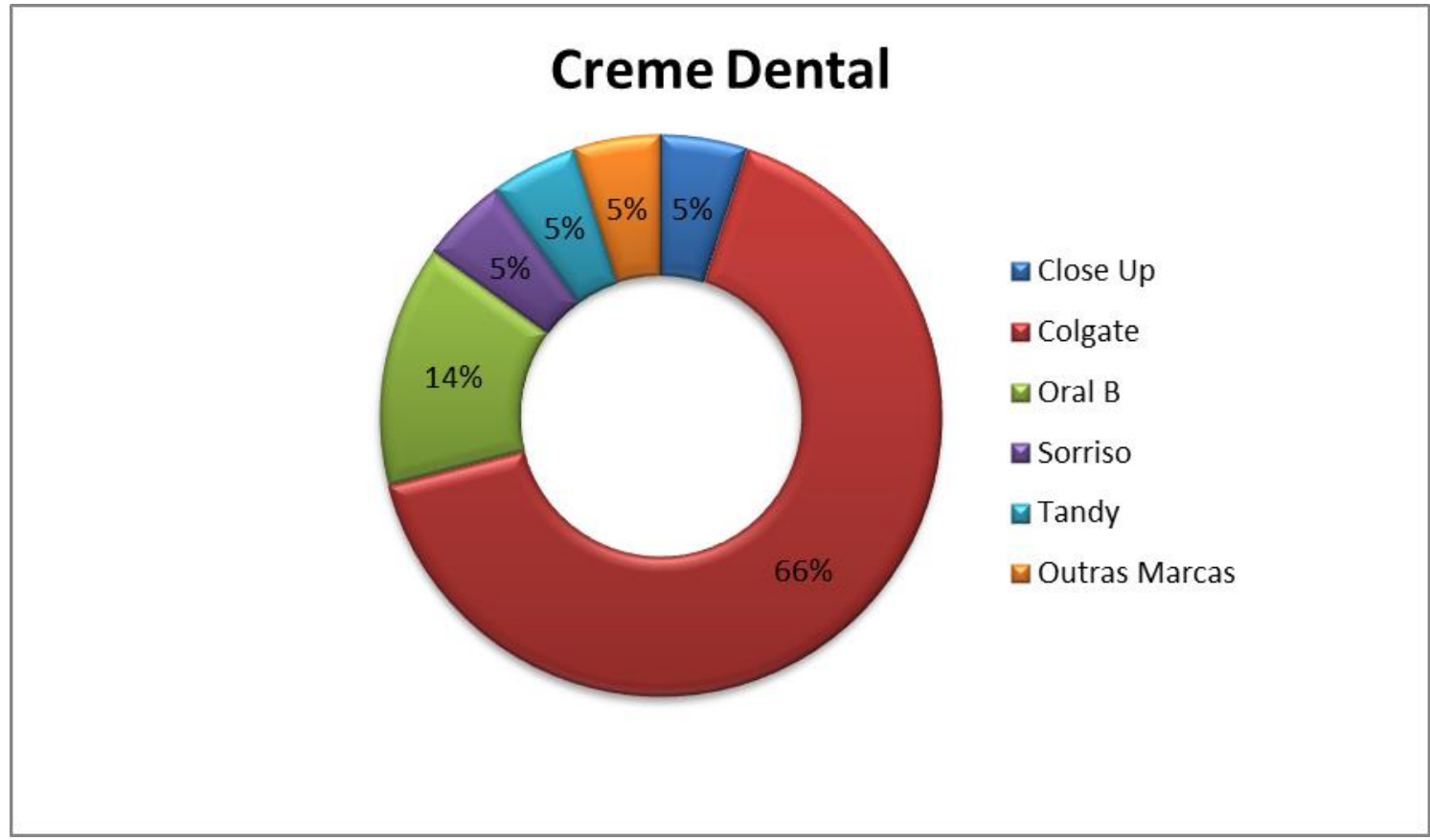

Fonte: Autores, 2022.

\section{DISCUSSÃO}

O uso da escova dental é fundamental na higiene oral, entretanto, este instrumento pode ser fonte de contaminação quando não armazenadas de forma adequada, o que foi observado nesta pesquisa, onde apresentou crescimento de microrganismos em todas as escovas dentárias (GONÇALO; MIALHE, 2009).

No presente estudo, a maioria dos voluntários armazenava a escova dental em um recipiente sobre a pia, enquanto os demais faziam esse armazenamento em armários (35\%). Setenta por cento relataram secar a escova após o uso, enquanto $30 \%$ não realizava a secagem; mesmo nas escovas dos indivíduos que relataram uso de capa protetora houve contaminação $(35 \%)$. A marca de dentifrício mais utilizado pelos voluntários foi a Colgate ${ }^{\circledR}$. Além disso, os microrganismos de maiores prevalências nessas escovas foram o Staphylococcus aureus, seguido do Staphylococcus epidermidis e Enterobacter sp. Desta forma, sem os devidos cuidados após a utilização da escova há contaminação independente do local que ela será armazenada (QUEIROS; PASSOS, 2019).

$\mathrm{Na}$ literatura, não há um padrão estabelecido para a descontaminação de escovas dentais, embora haja alguns materiais que podem ser usados para a desinfecção. Tem-se descrito o uso do álcool a $77 \% \mathrm{v} / \mathrm{v}$, ou uma solução de vinagre branco (ácido acético) diluído a $50 \%$ em água deionizada esterilizada, uma solução de dentifrício (diluição de $5 \mathrm{~g}$ do dentifrício em $20 \mathrm{ml}$ de água deionizada esterilizada), e ainda a possibilidade de imersão em água fervente durante dez minutos; 


\section{RECIMA21 - REVISTA CIENTÍFICA MULTIDISCIPLINAR ISSN 2675-6218}

além destes, o uso de antissépticos à base de gluconato de clorexidina na concentração $0,12 \%$ com uso em spray, para que haja economia, também é relatado. Foi constatada a eficiência e o baixo custo do hipoclorito de sódio (água sanitária) e do acido acético (vinagre) no processo de desinfecção das escovas dentais, porém, a água sanitária não é indicada para a utilização diária, pois pode ocasionar irritações na mucosa bucal e desencadear problemas estomacais, caso a escova não tenha sido abundantemente enxaguada (GOLÇALVES et al., 2019; GONÇALO; MIALHE, 2009; QUEIROZ et al., 2013).

No caso do SARS-CoV-2, diferentes enxaguatórios bucais estão sendo avaliados quanto à eficácia em reduzir a carga viral oral. Contudo, ainda não há dados disponíveis sobre o uso de substâncias para a desinfecção de escovas dentais. Os enxaguatórios bucais a base de clorexidina não demonstraram eficiência contra esse vírus. Testes in vitro e sugeriu o uso do enxaguatório oral contendo etanol e óleos essenciais (Listerine $\mathrm{Cool} \mathrm{Mint}^{\circledR}$ ) como primeira escolha para desinfectar as escovas dentais, imergindo suas cerdas por 20 min após a escovação. Em ambientes coletivos, como escolas, creches, hospitais e casas de longa permanência para idosos, após a higienização das mãos, é recomendado a limpeza do cabo da escova com álcool 70\% por 1 minuto (TEIXEIRA et al., 2021).

A American Dental Association (ADA) ressalta a importância de cuidados essenciais, como não compartilhar escovas dentais, não as armazenar próximas uma das outras sem proteção, para evitar contaminação cruzada, enxaguar com água corrente para retirada de todo o creme dental e detritos após a escovação, armazenar na posição vertical, assim como não as deixar em ambiente úmido e fechado (ADA, 2006).

Junto à realização da instrução de higiene oral, é necessária a orientação quanto à higiene e armazenamento das escovas dentais, haja vista que foi verificada que boa parte dos estudantes do curso de Odontologia não secam as cerdas das escovas, nem utilizam qualquer produto desinfetante após sua utilização, fato que ressalta a lacuna presente na formação acadêmica sobre o tema o que acarreta no prejuízo das orientações aos pacientes sobre os cuidados com a escova dental (GONÇALO; MIALHE, 2009; MIALHE et al., 2007).

As escovas podem estar contaminadas desde a primeira escovação, com isso, podem atuar como reservatório de microrganismos, e ocasionar contaminação cruzada, assim como carrear microrganismos de locais infectados para outros não infectados, e propiciar a exacerbação de algumas doenças (GONÇALO; MIALHE, 2009).

Os microrganismos residentes da cavidade oral, além de serem potencialmente patogênicos neste local, também estão associados a doenças extrabucais. Alguns fatores influenciam na patogenicidade dos microrganismos, como a diversidade de superfícies da cavidade bucal (superfície dental, língua, mucosas), presença de imunossupressão, hospitalização longa e a idade (APOLÔNIO; MACHADO, 2018; FERREIRA et al. 2013). 


\section{RECIMA21 - REVISTA CIENTÍFICA MULTIDISCIPLINAR ISSN 2675-6218}

Outrossim, a descontaminação correta pode prevenir a transmissão de doenças com risco potencial elevado à saúde do indivíduo, como a sífilis, difteria, tuberculose, hepatites, AIDS, faringite, hepatite $C$, além de endocardite bacteriana, doenças cardíacas, derrame cerebral e infecções crônicas (GONÇALO; MIALHE, 2009).

\section{CONSIDERAÇÕES FINAIS}

Todas as escovas avaliadas apresentaram algum tipo de contaminação, independente da forma de armazenamento, sendo os principais microrganismos identificados: Staphylococcus aureus, Staphylococcus epidermidis e Escherichia coli. Ainda não há um consenso sobre qual a melhor e mais acessível opção para a descontaminação da escova dental.

Desta forma, é evidente a necessidade de ampliar o conhecimento, desenvolver novos estudos que avaliem a forma mais eficaz de descontaminação e a divulgação sobre os cuidados adequados na utilização e conservação das escovas dentais.

\section{REFERÊNCIAS}

ADA Division of Communications. Toothbrush care, cleaning and replacement. J Am Dent Assoc, v. 13, n. 3, p. 57-65, 2006.

APOLÔNIO, A. C. M.; MACHADO, A. B. F. Microbiologia Bucal e Aplicada. São Paulo: Santos, 2018.

ARAÚJO, R. J. G. et al. Contaminação, desinfecção e acondiconamento de escovas dentais. Revista Científica da ABOMI, v. 29, n. 1, p. 44-54, 2014.

BALAPPANAVAR, A. et al. Antimicrobial Efficacy of Various Disinfecting Solutions in Reducing the Contamination of the Toothbrush - A Comparative Study. Oral Health Prev Dent, v. 7, n. 2, p. 137145, 2009.

FERREIRA, G. T. S. et al. Verificação da contaminação e forma de armazenamento de escovas dentais em um grupo de adolescentes de uma escola da rede privada de ensino. Rev. odontol. Univ. Cid. São Paulo, v. 25, n. 1, p. 6-10, 2013.

GONÇALO, C. S.; MIALHE. F. L. Contaminação das escovas dentais: uma revisão crítica da literatura. Revista Periodontia, v. 19, n. 3, p. 56-63, 2009.

GONÇALVES, G. H. et al. Contaminação, meios de desinfecção e armazenamento da escova dental: revisão de literatura. Revista de Iniciação Científica e Extensão, v. 2, n. 4, p. 219-227, 2019.

GONZÁLEZ-OLMO, M. J. et al. Oral hygiene habits and possible transmission of COVID-19 among cohabitants. BMC Oral Health, v. 20, p. 286, 2020.

LAMARCA, J. H. et al. SARS-CoV-2: a protocol for disinfection of toothbrushes. The Journal of Infectious Diseases, 2020.

MARIN, C.; MICHELS, B. Desgaste e armazenamento das escovas dentais numa unidade oncológica infantil. RSBO, v. 14, n. 2, p. 108-115, 2017. 


\section{RECIMA21 - REVISTA CIENTÍFICA MULTIDISCIPLINAR ISSN 2675-6218}

AVALIAÇÃO DA CONTAMINAÇ̃̃ POR MICRORGANISMOS PATOGÊNICOS E CUIDADOS COM ESCOVAS DENTAIS Amanda da Silva Nunes da Conceição, Alicia da Silva Nunes da Conceição, Michelle Silva de Oliveira, Diego de Andrade Teixeira, Amanda da Silva Nunes da Conceição, Alicia da Silva Nunes da Conceição, Michelle Silva de Oliveira, Diego de Andrade Teixeira,
José Massao Miasato, Leila Chevitarese, Luciana Alves Herdy da Silva, Flávia Cariús Tesch Ferreira Alves, Silvio Jorge Machado

MIALHE, F. L. et al. Avaliação dos cuidados relativos ao armazenamento e desinfecção das escovas dentais por acadêmicos de Odontologia. Revista de Odontologia da UNESP, v. 36, n. 3, p. 231-235, 2007.

MOREIRA, A. C. S.; CAVALCANTE, G. M. Influência da higienização na contaminação de escovas dentais. Arq. Ciênc. Saúde Unipar, v. 12, n. 1, p. 99-103, 2008.

PINTO, E. D. R. et al. Viabilidade de microorganismos anaeróbios da cavidade bucal em escovas dentárias. Periodontia, v. 6, n. 1, p. 8-12, 1997.

QUEIROS, E. C. F.; PASSOS, M. A. N. Aspectos de contaminação e descontaminação das cerdas de escovas dentais. Revista Ciências e Odontologia, v. 3, n. 1, p. 1-5, 2019.

QUEIROZ, F. S. et al. Avaliação do perfil de armazenamento e descontaminação das escovas dentais. Revista de Odontologia da UNESP, v. 42, n. 2, p. 89-93, 2013.

SANCHES, M. H. et al. Descontaminação das escovas dentárias por imersão em soluções antissépticas. Revista gaúcha de Odontologia, v. 46, n. 3, p. 167-171, 2001.

SATO, S. et al. Bacterial survival rate on toothbrushes and their decontamination with antimicrobial solutions. J. Appl. Oral Sci, v. 12, n. 2, p. 99-103, 2004.

SILVER, J. G. et al. Experimental transient bacteraemias in human subjects with varying degrees of plaque accumulation and gingival inflammation. J Clin Periodontol, v. 4, n. 2, p. 92-99, 1977.

SIQUEIRA JÚNIOR, H. M. et al. Os microorganismos contaminam as escovas dentais?. HU Revista, v. 37, n. 4, p. 409-412, 2011.

SOARES, P. V. et al. Avaliação da contaminação de escovas dentais por microrganismos e da efetividade de antissépticos na sua descontaminação. Revista Brasileira de Pesquisa em Saúde, v. 12 , n. 3, p. 5-10, 2010.

TEIXEIRA, D. A. et al. Avaliação da microbiota presente nas escovas dentais de pacientes infantis durante a internação hospitalar: Estudo piloto. Research, Society and Development, v. 10, n. 9, p. e4210917615, 2021. 